\title{
CORRESPONDENCE
}

Correspondents are asked to be briet

Thyroid Scanning

K. E. Britton, M.D., M.SC., M.R.C.P., and P.

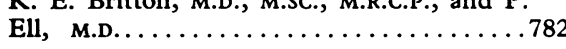

Coma and Convulsions Associated with Vincristine Therapy

J. Martin, M.R.C.P., and Dorothy Mainwaring,

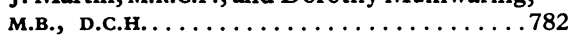

Pyrimethamine Poisoning

J. Armata, M.D...............783

Diathermy Burn Hazard

A. G. Nash, F.R.c.s. . . . . . . . 783

Drugs and Dementia in the Elderly

B. F. B. Russell, M.D. . . . . . . . . . . 783
Anaemia in the Elderly

J. H. Thomas, M.R.C.P...........783

Doctors in South Africa

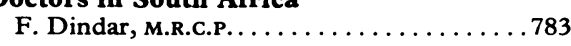

Making Hospital Geriatrics Work

P. P. Mayer, M.R.C.P. . . . . . . . . . 784

Home Graduates Only

K. Raghavan, M.B..............784

High Dose Frusemide in Established Acute Renal Failure

Y. K. Seedat, M.D. . . . . . . . . . . . .784

F.D.P. Levels in Intravascular Haemolysis

E. N. Wardle, M.R.C.P...........784
Analgesics and the Kidney

R. A. Axelsen, M.B., and A. F. Burry, M.D. . 784

Suppository Inserter: New Aid for the Disabled

A. T. Day, M.R.C.G.P...... . . . 785

Abortion in 1972

P. L. C. Diggory, F.R.C.s. . . . . . . . . . 785

Adoption Problems

M. Phillida, T. Sawbridge, B.A., and Wanda

McClanahan, M.S.w.(U.S.A.). . . . . . . 785

Seat Belt Syndrome

J. M. Shennan, F.R.C.s. . . . . . . . . 786

Think Again on Salmon

L. J. Temple, F.R.C.s. . . . . . . . . . 786
SIR,-The appearance, within a month, of a leading article on "The Solitary Thyroid Nodule" (10 November, p. 31) and a clear survey of the "Clinical Diagnosis of Thyroid Cancer" (Messrs. M. D. Staunton and W. P. Greening, 1 December, p. 532) calls for comment on their differing advice regarding the scanning of the thyroid. The first, having reviewed the incidence of cancer in solitary nodules, considers that "it should be possible to predict with some accuracy today what lesions ought to be removed surgically" and goes on to state that "the thyroid should be scanned, and if the nodule is solitary and 'cold' that is probably a firm indication that surgery is indicated" (our italics). The second quotes Werner's ${ }^{1}$ statement that "isotope scanning has achieved no high degree of predictability in the diagnosis of thyroid cancer." The hope and the fact are stated.

Will a thyroid scan diagnose a nodule to be solitary? Let us assume that the resoultion of a scanner or gamma camera is such that it will pick up "cold" areas in the thyroid down to $0.5 \mathrm{~cm}$ diameter. What effect does a nodule of $0.4 \mathrm{~cm}$, which may be palpable, have on this approach? Does or does not the presence of an undetected nodule $0.4 \mathrm{~cm}$ across invalidate the concept of the solitary nodule? Multiplicity of nodules does not exclude cancer. Surely if there is sufficient clinical suspicion of cancer to warrant requesting a scan, there is sufficient clinical suspicion to demand histological examination of that gland, whatever the scan shows.

In defence of the scan it may be argued that the discovery of a "cold" nodule $(90 \%$ of the total according to Messrs. Staunton and Greening) will save an operation on a "hot" nodule. A truly "hot" nodule is autonomous and, if it is nor already causing hyperthyroid function (diagnosable by the relevant blood tests), it will probably grow to do so. Surgery here is the treatment of choice at least up to the age of 45 .

What then is the place of thyroid scanning? It is to be used when there is a mass outside the usual position of the thyroid being used to prolong the time so necessary for the decision-making process, or as something extra for a visiting consultant to request as another patient-bed-day slips by?

It is now so easy to suggest and send a request to a diagnostic department that serious reflection on how the result is likely to affect the clinical management, the time off work of the patient, and the economics of the Health Service may be short-circuited. As evidence of lack of reflection, the filling up of a request form accurately and with relevant information has become a literary exercise involving such a high degree of concentration and manual labour that it appears to be beyond the ability of so many.-We are, etc.,

KEITH BRITTON PETER Ell

Institute of Nuclear Medicine,

Middlesex Hospital Medical School,

London $\mathrm{W} .1$ directly to histological confirmation. Alternatively, shall we conclude that the thyroid scan (as are so many diagnostic tests) is Werner, S. C., in Thyroid, ed. S. C. Werner and
S. Ingbar. New York, Harper and Row, 1971.

\section{Coma and Convulsions Associated with Vincristine Therapy}

SIR,-We read with interest the recent article (10 November, p. 335) by Dr. J. A. Whittaker and others describing three cases of reversible coma after vincristine therapy. During the past six years we have seen five children in whom otherwise unexplained coma and convulsions occurred during or shortly after their first course of treatment with vincristine. Four of these children were receiving therapy for acute lymphatic leukaemia and the fifth child for nephroblastoma. Their ages ranged from three to 11 years. In each child the episode of coma with numerous convulsions occurred 2-10 days after a vincristine injection. In two children it was after the second injection, in two after the third, and in one after the fourth weekly injection. The dose given was $1.5 \mathrm{mg} / \mathrm{m}^{2}$ in three cases and $2 \mathrm{mg} / \mathrm{m}^{2}$ in two. Examination of the cerebrospinal fluid showed no significant abnormality in four of the five cases, but the E.E.G. was very disorganized in the four cases in which it was recorded. Electrolyte estimations in three cases showed no changes suggestive of inappropriate secretion of antidiuretic hormone. The period of coma lasted from 24 hours to seven days and all the children recovered completely from the episode. One child was given further vincristine injections, restarting 11 days after the convulsive episode, and had no subsequent reaction.

If our experience is typical it would suggest that these neurological complications of vincristine are by no means as rare as the reports in the literature suggest. The incidence is difficult to estimate, but we treat approximately 25-30 new patients with vincristine each year and have seen this complication five times in six years. It is important to be aware of this possibility in patients receiving vincristine as otherwise 